Received Date: January $2020 \quad$ Revised: March $2020 \quad$ Accepted: June 2020

\title{
Methods of Population Estimation and Projection
}

Gokarna Raj Aryal (M. Phil.)*

\section{Abstract}

This research paper tries to clarify the differences between population estimation and projection. The main objective of this study is to introduce basic concept of population estimation and projection. It also explains the tools and techniques for estimation and projection of population in both regional and national levels. However, the perception of population estimation and projection is frequently confusing to the readers. Though the difference between the two is relatively normal and straightforward. Both concepts generate numbers that is intended to indicate the size of the population of a given geographical area at a specific point of time. Most of the developing countries, censuses are taken at every ten years' interval. Major changes of demographic events and features of the population are obtained for short periods. In this way, the foremost purpose of this study is to provide reliable and satisfactory projected data in both provincial and national levels. Various tools and techniques have been developed for estimation and projection of population i.e. mathematical, economic and cohort component. These techniques require accurate data and reliable information related to the fertility, mortality and migration of the country. In conclusion, the reliable projected data are vital for business and program planning, transparency, prosperity, policy discourse and good governance in different sectors of the nation for the upcoming days.

Key words: Population, assumption, technique, estimation, projection, variant $\&$ type.

\section{Introduction}

Population estimation refers to the size of current population in the specific area. Population estimation is usually based on direct components of population change such as the actual number of births and deaths occurring between the date of the previous population censuses and the date of the estimation. In the absence of direct data, population estimation is based on symptomatic indicators of the components of population change such as changes in school enrollments or the number of means of transportation registered.

*Mr. Aryal is a Lecturer and Head at the Department of Population Studies, Patan Multiple Campus, TU, Lalitpur, Nepal.Email: goaryal243@gmail.com 
The term 'projection' refers to any carefully constructed approximation to the future size and characteristics of the population of a specific area. Some projections are intended by the analyst to represent merely the consequences for population size, and characteristics of the application of a set of demographic or mathematical assumptions to population census or post censual estimation. Many projections, however, are intended as forecasts or can reasonably be interpreted as forecasts that is predictions of population numbers. Population projection is defined as the numerical outcome of a specific set of assumptions regarding future trends of fertility, mortality and migration.

Population projection and estimation contributes to the activities of government, organizations and business persons. It also plays the most essential role for planning and policy making process of the nation (Rowland, 2003). Social scientists, administrators and planners have a vital need for current estimations and projections of socio-economic and health, and demographic characteristics. It is useful in the field of administrative programs related to public welfare, education, health, public safety and transportation (Siegel, 2002).

Population projection has been prepared using seven types of input data. They are: smoothed age-sex distribution of base year population, sex ratio at birth, age-specific fertility and total fertility rate, life expectancy at birth, model life table pattern and net migration. Trends of fertility, mortality and migration for subsequent years are assumed based on available sources and plausible estimations. As various combinations of assumptions are applied on fertility, mortality and migration; population projections are prepared in various settings as well. Therefore, three scenarios of population projections namely high, medium and low variants are obtained for all age, sex and spatial area with an interval of five years' time period and also, for five years' age distribution. A computer program known as Spectrum is used for making population projection at the national level. However, reliable data about the components of the population are not available at sub-national level such as: the cohort-component method cannot be used for sub-national population projection (CBS, 2014).

\section{Problems of the Study}

In most of the developing countries like Nepal, censuses have been taken at decennial intervals and they provide information about the size and structure of the population during census years. However, the major changes in the numbers, distributions and characteristics of national population can occur in short periods. In such situation, we can estimate national population by using various techniques. The mathematical methods do not provide population projection by age and sex. This method is not considered 
reliable or satisfactory because it does not concern about past and future trend of fertility, mortality and migration. In such situation, cohort component method is used as it provides population projections by age and sex and it has greater analytical values in understanding developments and the relative contributions of growth from different sources.

The estimations are accurate if data used are reliable and assumptions involved in the projections hold truth in reality. Hence, data need to be properly evaluated and adjusted for errors before using for projection and the most likely assumptions need to be made. However, the most plausible assumptions used in the projection will not be exact in reality. As such, other alternative assumptions have to be used. The various combinations of assumptions about fertility, mortality and migration lead to a large number of population projections.

\section{Objectives}

The main objective of this study is to explain the tools and techniques for estimation and projection of population in regional and national levels. The specific objectives of this study are to introduce basic concepts related to population estimation, projection and its types for the upcoming days.

\section{Justification}

Population estimation and projection are essential in developing countries than in the developed one. The data are updated and vivid in the developed countries whereas it is not reliable and updated in the developing countries. The data are needed to the government, non-governmental organizations and private sectors. Any governments have a primary task designing a livable future for the population of a community. To achieve this, population projection must be converted ultimately into measures of the future need for water and sewage facilities, housing, hospitals, post offices, schools, and other community facilities. The development of such figures may entail, as an intermediate step, the preparation of projections of households, families, income distribution, educational level and labor force. Projections are based on the assumptions that the past trends will continue to operate in the future. There are several methods for the projection of national and sub-national population. Some widely used methods are Cohort Component Method, Geometric Method, Exponential Method and Ratio Method.

The demographers' important task is to provide information on the future trend of population that is essential to plan for several aspects of human activities. Population projection is a workout at calculating the future values of given population. The fundamental stage in the process of projection is at the formulation of a set of realistic assumptions regarding 
the future trajectory of a population as well as of the rates that would determine its growth and change. The reliability of the projected data will depend upon the validity of these assumptions and the accuracy with which these assumptions are translated into quantities terms.

Population projection predicts what type of changes can occur, given assumptions inherent in the projection method and data. Here, projection refers to the size of the population at some point in the future, they aren't based on actual data as compared to the components of population change. Moreover, they must be relied on an extension of either current or expected population trends into the future. Experts typically cultivate more than one set of projections, each set expressing different assumptions. Projections might signifies minimum, midpoint and maximum growth rates, but all projections should be reasonable.

\section{Data and Methods}

This study is based on secondary data collection which is obtained from previous studies, relevant journals and census reports etc. In this study, existing literatures related to population estimation and projection is extensively reviewed. The collective data and descriptive information are presented in different ways.

\section{Population Estimation and Projection}

\section{Population Estimation}

Population estimation methods are tied up in two types i.e. inter-censual and post-censual estimation. Post-censual estimations are prioritized but inter-censual estimations are used in several cases. Inter-censual estimation provides a tactic of estimating the population of the area on a year by year basis for the inter-censual period. Post-censual estimations tie up estimating the population of an area after the most recent census or some other base period up to a point in the recent past. Data of post-censual estimations are more likely to be favored by administrators, planners and other similar usages of population data.

\section{Population Projection}

A population projection is an estimation of the number of people expected to be alive at a future date that is made based on assumptions of population structure, fertility, mortality and migration. It is an essential to assess the need for new jobs, schools, doctors and nurses, planning urban housing, foods, clothing and requirements of energy and resources. It is also needed for policy discourse i.e. helps to the policy-makers to understand the existing problems and finally supports to develop the suitable solutions. 


\section{Types of Population Projections}

Population projection is empirically based on calculations of past or future, population numbers under specified assumptions about changes in population growth or its components. Basically, there are three techniques for population projection: Mathematical Method, Economic Method and Cohort Component Method.

\section{Mathematical Method}

Mathematical method is frequently used for the estimation of population. It is done for short period i.e. less than 10 years. The major assumptions of these methods are: the socio-economic setting affecting to the population size is fairly unchanging, no allowance is made for the irregular fluctuations in the population growth and same growth rate continues for the projection period. Furthermore, mathematical methods are used for intercensual, post-censual estimates and future population for shorter period and projection for sub-national population (Bhattarai et al., 2019).

The mathematical method uses various statistical formulas where the population projection of these methods does not provide the population projection by age and sex as it does not assimilate the past and future trends of fertility, mortality and migration. Some basic techniques of these methods are as follows:

a) Linear Growth Model (Arithmetic Growth Model)

$$
P_{t}=P_{0}(1+r t)
$$

b) Geometric Growth Model

$$
P_{t}=P_{0}(1+r)^{t}
$$

c) Exponential Growth Model

$$
P_{t}=P_{0} e^{r t}
$$

d) Gompertz Curve

$$
P_{t}=a b^{c^{t}}
$$

e) Modified Exponential Function

$$
P_{t}=a+b c^{t}
$$


f) Makeham's Curve

$$
P_{t}=\log \left(a+b c^{t}\right)
$$

g) Polynomial of Degree $n$ :

$$
P_{t}=a_{0} t^{0}+a_{1} t^{1}+a_{2} t^{2}+a_{3} t^{3}+\ldots \ldots \ldots \ldots+a_{n} t^{n}
$$

h) Logistic Growth Model

$$
P_{t}=\frac{K}{\left(1+e^{a+b t}\right)}
$$

Where,

$$
\begin{aligned}
& P_{t}=\text { current year population } \\
& P_{0}=\text { base year population } \\
& r=\text { growth rate } \\
& t=\text { time interval (in years) } \\
& \boldsymbol{e}=\text { base of the natural logarithms }
\end{aligned}
$$

\section{Cohort Component Method}

The cohort-component technique is a complex method for the population projection. It is the most frequently used method for projecting the population of nations, states, and sometimes smaller units of geography (Shryok \& Siegel, 1973). It is the preferred method of national and international statistical organizations for projecting national population. This method is also useful for sub-national projection. Moreover, it provides projections by age and sex, the method is equally applicable at national and sub-national levels, it makes sufficient use of accessible statistical information on the components of population change. Furthermore, it has immense analytical value in understanding developments and the relative contributions of growth from different sources. At the same time, the method is flexible: assumptions can be varied according to expectations about future directions of change in specific components.

Like most projection tools and techniques, there are some disadvantages in using the cohort component method. First, it is highly dependent on reliable birth, death and migration data. Thus, it is difficult to collect the information to apply this tool. Second, it assumes that survival, birth rates and estimations of net migration will remain the same during the projected period. 


\section{Economic Method}

Mathematical Method and Cohort Component Method of population projections require basic information of annual population growth, birth, death and migration rate. However, the factors really affecting them are not taken into consideration to the projected statistical information remains dynamic. Consequently, this method tries to explain how economic factors influence the demographic factors i.e. birth, death and migration rates. Economic development is more significant to know the effects of migrations.

In most of the developing countries, people migrate from the backward areas to developed areas in search of jobs and opportunities. In addition, the rural, urban, age and sexwise number of projected labors are to be forecasted. These deviations, their effects on urbanization and the consequent growth of towns, cities and urban centers and birth rate, death rate and growth rate of population in them are projected. This method is more essential for province-wise projections relatively than for the entire country. Among the various methods, it is also an essential techniques for national population projection but it is less applicable method.

\section{Conclusion}

It is difficult to achieve reliable, valid and updated data in most of the developing countries like Nepal. Likewise, accurate and consistent information are inevitable to the planners, policy makers, administrators, business professionals and educators for effective decision-making process for the nation. Population estimation and projection, to some extent, provides these types of information of the country. It is an essential tool for projecting to the future size and structure of population at national, provincial, regional, local community and civil society. It is also needed to the agencies and organizations engaged in public as well as private activities. Moreover, it is also useful techniques for program planning and policy discourse.

The methods that are projected for population projection and estimation are of three typesmathematical, economic and cohort component. The mathematical methods are generally applicable techniques which consists many tools. It doesn't provide the population projection by age and sex and assimilate the past and future trends of fertility, mortality and migration. Economic method tries to describe the way how economic factors influence the demographic factors i.e. birth, death and migration. It is less applicable method in our society.

The cohort-component method is usually used method. It is the preferred method for national and international statistical organizations to project the national population. It 
is also useful for sub-national and national population projection. Moreover, it provides projections of population by age and sex of the nation. Furthermore, it has immense analytical value in understanding developments and the relative contributions of growth from different sources. This method requires precise data and consistent information related to the fertility, mortality and migration of the country. This is the burning issue in $21^{\text {th }}$ century in the Globe. The reliable projected data for upcoming days is essential for good governance, business, transparency and prosperity and policy formulation in different sectors of the nation.

\section{References}

Bhattarai, D. K., Acharya, B., Poudyal, K. A., \& Paudel, R. (2019). Demography for health and social sciences. Kathmandu: Koselee Prakashan, Bagbazar, Nepal.

Central Bureau of Statistics (CBS). (2003). Population monograph of Nepal 2001. Kathmandu: National Planning Commission Secretariat, Central Bureau of Statistics, Nepal.

Central Bureau of Statistics (CBS). (2014). Population monograph of Nepal 2011, Vol. I, II \& III. Kathmandu: National Planning Commission Secretariat, Central Bureau of Statistics, Nepal.

Ministry of Population and Environment (MoPE). (2003). Population projections for Nepal 2001-2021. Kathmandu: MoPE, Nepal.

Rowland, D. T. (2003). Demographic methods and concepts, 2003. New York: Oxford University Press Inc., United States.

Shryok, H. S., Siegel, J. S., \& Associates (1976). The methods and materials of demography. New York: Academic Press Inc., United States.

Siegel, J. S. (2002). Applied demography: Applications to business, government, law and public policy. New York: Academic Press, United States.

United Nations (UN). (1983). Manual X: Indirect techniques for demographic estimation. New York: Department of International for Economic and Social Affairs, UN, United States. 